- Used dental burs may be contaminated with potentially pathogenic micro-organisms.

- Autoclaving alone fails to completely decontaminate burs.

- Manual cleaning is not as effective as other methods of pre-sterilisation cleaning.

- Enzymic agents may have a role in the decontamination process.

- Washer-disinfectors are the most effective method of pre-sterilisation cleaning for contaminated dental burs.

\title{
A comparison of decontamination methods used for dental burs
}

\author{
C. L. Whitworth, ${ }^{1}$ M. V. Martin, ${ }^{2}$ M. Gallagher ${ }^{3}$ and H. V. Worthington ${ }^{4}$
}

Objectives This study investigated the bacterial and fungal contamination of used dental burs. A novel assay system for comparison of efficacy of pre-sterilisation cleaning techniques for dental burs was used to evaluate manual scrubbing, enzymic agents and washerdisinfectors.

Methods Thirty dental burs contaminated during cavity preparation were analysed for micro-biological total viable counts and species of bacteria and fungi present. To simulate clinically contaminated burs, a culture of Streptococcus sanguis NCTC 7863 was used to inoculate unused dental burs, alone and combined with blood, saliva or a mixture of blood and saliva. Contaminated burs were subjected to six presterilisation cleaning techniques and the log reduction in contamination achieved by each method was assessed.

Results The microbial count from used dental burs ranged from 0 to $6.92 \times 10^{4} \mathrm{CFU} \mathrm{ml}^{-1}$. Many potentially pathogenic species were identified. The decontamination assay demonstrated that autoclaving alone was not sufficient to sterilise dental burs. Manual scrubbing in air was less efficacious than manual scrubbing under water $(p<0.001)$. The most effective method of pre-sterilisation cleaning for dental burs was a washer-disinfector.

Conclusions Enzymic agents are suitable for soaking contaminated dental burs immediately after use. Washer-disinfectors are recommended as the method of choice for pre-sterilisation cleaning of contaminated dental burs.

\section{INTRODUCTON}

Dental practitioners are required by national guidelines to sterilise instruments contaminated with blood or saliva during dental procedures. ${ }^{1}$ It is now recognised that the most important pre-requisite to sterilisation is satisfactory pre-cleaning. ${ }^{2,3}$ Residual organic contamination insulates blood-borne pathogens from the effects of sterilisation by heat, posing a risk of cross-infection.

\footnotetext{
${ }^{1}$ General Dental Practitioner, 9 Rake Lane, Upton, Wirral, ${ }^{2}$ Senior Lecturer, ${ }^{3}$ Medical Scientific Officer, University of Liverpool, Clinical Dental Sciences, ${ }^{4}$ Professor of Evidence Based Care, University Dental Hospital of Manchester

${ }^{*}$ Correspondence to: C. L. Whitworth, 9 Rake Lane, Upton, Wirral CH49 OUS

Email:cwblackadder@btinternet.com
}

\section{Refereed paper}

Received 2.04.03; Accepted 28.10.03

doi:10.1038/sj.bdj.4811832

(๑) British Dental Journal 2004; 197: 635-640
Dental burs may become heavily contaminated with necrotic tissue, saliva, blood and potential pathogens during use. ${ }^{4}$ Burs have a complex architecture that makes pre-cleaning and subsequent sterilisation difficult to achieve. ${ }^{5}$ Published studies have investigated artificially contaminated instruments subjected to various cleaning techniques. Soaking in chemical germicides does not decontaminate burs. ${ }^{6,7}$ Ultrasonication with or without chemical disinfectant solutions, even with pre-soaking, is insufficient to remove all contamination. ${ }^{8,9}$ In addition to the risk of cross-infection between patients due to inadequate sterilisation, puncture wounds caused by dental burs are not uncommon, both in use and during cleaning, leading to a risk of transmission of disease between patients and dental personnel. ${ }^{10}$ Previous research has concentrated on corrosion and deterioration of cutting efficiency of burs as a result of chemical disinfection and autoclaving. ${ }^{11} \mathrm{~A}$ multiphase decontamination process has been suggested for dental burs, but there are no published results to support this recommendation. ${ }^{12}$ An audit of infection control procedures demonstrated that some general dental practitioners fail to pre-clean burs prior to autoclaving and that a significant proportion of dentists rely on disinfection only. ${ }^{13}$

The purpose of this investigation was to qualitatively and quantitatively assess bacterial and fungal contamination of three different types of burs used for cavity preparation in general dental practice. An assay system was devised for comparison of the efficacy of various methods of pre-cleaning and sterilising dental burs in order to establish a suitable method for decontamination of burs used in dental practice. The pre-sterilisation cleaning methods selected for inclusion in this study were manual cleaning, enzymic agents and washer-disinfectors. Ultrasonication was not included because previous research has shown that this method failed to remove blood and tooth debris from contaminated burs. ${ }^{14}$

\section{MATERIALS AND METHODS \\ Dental burs}

The dental burs used in this study were the No.541 diamond bur, (Hi-Di, Dentsply Ltd, Weybridge, Surrey), No.8 round head carbon steel bur (UnoDent, Witham, Essex) and No.246 tungsten carbide bur (Jet, Kerr Dental, Orange, California, USA). The bur types tested were the best-selling varieties of burs identified by major dental supply companies. 


\section{Sampling}

An unused bur was placed in a sterilised handpiece using sterile tweezers and was used for cavity preparation. The site and nature of the cavity preparation done and the length of time that the bur was in contact with the tooth were noted. After use, the bur was removed from the handpiece with sterile tweezers and placed in a Transwab sterile tube (Medical Wire and Equipment Co. Ltd., Corsham, Wiltshire) for transfer to the laboratory; no longer than $3 \mathrm{~h}$ elapsed between bur use and laboratory testing. An unused bur of the same type as used for tooth preparation was placed in a sterile tube of transport medium as a control. Ten burs of each type were tested.

\section{Microbiology}

Each bur was removed from the transport tube and placed in a sterile $5 \mathrm{ml}$ glass bottle containing $2 \mathrm{ml}$ Brain Heart Infusion (BHI) broth (Lab M, Bury, Lancashire). The bottle was vortexed for $90 \mathrm{~s}$. Four $100 \mathrm{ml}$ samples were taken from each bottle. Duplicate $100 \mathrm{ml}$ samples were plated onto 5\% (v/v) horse blood Chocolate Agar and incubated at $37^{\circ} \mathrm{C}$ in $5 \%(\mathrm{v} / \mathrm{v}) \mathrm{CO}_{2}$ for $5 \mathrm{~d}$. The remaining $100 \mu \mathrm{l}$ samples were plated out on Fastidious Anaerobic Agar (FAA) and incubated at $37^{\circ} \mathrm{C}$ in an anaerobic cabinet (Don Whitley Scientific Ltd., Shipley, West Yorkshire) for $5 \mathrm{~d}$. A colony count was then done for each plate. The mean number of colony forming units per $\mathrm{ml}$ (CFU ml-1) was calculated by adding the colony counts from each plate dividing the sum by four and then multiplying the mean count by twenty. Presumptive identification of the various bacteria and yeasts present was done by Gram staining and subculture of single discrete colonies. Streptococci were identified using the API-20 strep system, staphylococci with the API-20 staph system, anaerobes with the API-32 A system and yeasts with the API-32 C system (API-bioMerieux Ltd, Basingstoke, Hampshire).

\section{Decontamination assay}

The test bacterium used was Streptococcus sanguis NCTC 7863. On receipt, this strain was grown on 5\% (v/v) Columbia Blood agar base No.1 (Oxoid, Basingstoke, Hampshire) in an atmosphere of $5 \%(\mathrm{v} / \mathrm{v}) \mathrm{CO}_{2}$ at $37^{\circ} \mathrm{C}$ for $18 \mathrm{~h}$. For long-term storage, the bacteria were maintained by lyophilisation. For immediate use $S$. sanguis was subcultured every $14 \mathrm{~d}$. After four subcultures, the bacteria were replaced from freeze-dried ampoules to ensure that phenotypic characteristics were constant and unchanged by repeated subculture.

A total viable count (TVC) was done by dilution on an overnight culture of $S$. sanguis incubated at $37^{\circ} \mathrm{C}$ in BHI broth which was then dispensed into 20 samples of $1 \mathrm{ml}$ in sterile $1.5 \mathrm{ml}$ micro-centrifuge tubes (Elkay Eireann, Costelloe, County Galway, Eire). The samples were centrifuged for $5 \mathrm{~min}$ in a Micro Centaur centrifuge (Thermo Optek UK, Crawley, Sussex). The supernatant was discarded and the pellet used. Forty-one unused burs were placed in a sterilised bur stand. The working end of each bur was contaminated with $1 \mu \mathrm{l}$ of culture slurry. The culture was allowed to air dry for 15 min under a sterile glass beaker. Ten burs were further challenged with $1 \mu \mathrm{l}$ of filtered human saliva. Saliva for this purpose was collected from one volunteer (CLW) and filtered through a sterile $0.2 \mathrm{~nm}$ glass fibre filter (Sartorius Instruments Ltd, Belmont, Surrey) into a sterile $1.5 \mathrm{ml}$ sterile micro-centrifuge tube. The additional contaminant for a further ten burs was $1 \mu \mathrm{l}$ of defibrinated horse blood and for the remaining ten was $1 \mu \mathrm{l}$ of a 50\% (v/v) mixture of filtered human saliva and defibrinated horse blood. The additional contaminants were allowed to air dry for $15 \mathrm{~min}$. The remaining eleven burs were not additionally contaminated. One bur from this latter group was used as the control.

Viable bacteria were recovered by placing contaminated burs individually in sterile $5 \mathrm{ml}$ glass bottles containing $2 \mathrm{ml}$ of BHI broth and vortexing the contents for $90 \mathrm{~s}$. Samples of $100 \mu \mathrm{l}$ from each bottle were plated out in duplicate by spreading the sample onto horse blood agar using a sterile glass spreader and incubated for $48 \mathrm{~h}$ in an atmosphere of 5\% (v/v) $\mathrm{CO}_{2}$. The TVC in colony forming units per $\mathrm{ml}\left(\mathrm{CFU} \mathrm{ml}{ }^{-1}\right)$ was calculated.

\section{Decontamination methods}

Downward displacement (non-vacuum) autoclaving

Contaminated burs of each type were placed in sterile bur stands and autoclaved for $3.5 \mathrm{~min}$ at $134^{\circ} \mathrm{C}$, unwrapped, in a GE224c VAC/Citomat 164 autoclave (Getinge, Skarhamn, Sweden). After autoclaving, the burs were allowed to cool to room temperature before placing in separate sterile bottles containing $2 \mathrm{ml} \mathrm{BHI}$ broth. One hundred burs of each type were tested.

\section{Manual scrubbing}

The effectiveness of manual scrubbing was investigated using a bur brush (Ash instruments, Dentsply Ltd, Weybridge, Surrey). Forty contaminated burs of each type were subjected to forty strokes of the bur brush by holding the bur with a sterile glove and brushing from the shank end to the working end. This technique was done in air and under water, the latter by immersing the bur in a large glass beaker containing tap water. The combined effect of manual scrubbing in air and autoclaving was tested on a further forty burs.

\section{Enzymic agents}

Enzymic agents contain proteases, lipases and amylases and are designed to digest organic debris, including bacteria.

The efficacy of soaking in two enzymic agents was tested. Gigasept Enzymatic (Schulke \&t Mayr GmbH, Norderstedt, Germany) and Alkazyme (Alkapharm UK, Penkridge, Staffordshire, UK) were dissolved in warm tap water at the concentration recommended by each manufacturer. Forty contaminated burs of each type were immersed in the solutions. Those burs immersed in Gigasept Enzymatic were soaked for $15 \mathrm{~min}$ and those in Alkazyme for $5 \mathrm{~min}$, according to the manufacturers' instructions for use. After soaking, the burs were rinsed four times in purified water before placing in separate $2 \mathrm{ml}$ bottles of BHI broth. The effectiveness of a combination of soaking in enzymic agents followed by autoclaving was also tested.

\section{Washer-disinfectors}

Washer-disinfectors for medical and dental use have a washing cycle for removing patient debris and a disinfection cycle that raises the temperature to a level that will destroy vegetative microorganisms. Washer-disinfectors must conform to BS 2745 and HTM 2030.

The machines tested were the Medisafe HSC-032 and the Miele G 7830 TD. Manufacturers' instructions were followed throughout processing. The cleaning agent used in the Medisafe HSC-032 was Decono-zyme gel, a mixed enzyme solution with isopropanol, monopropylene glycol and surfactants. The water softener was AWT liquid, containing sequestrants, citric acid and a wetting agent. The Miele G 7830 TD programmes were run using the Neodisher mediclean, whose ingredients include anionic surfactants, nitrilotriacetic acid and enzymes. Forty contaminated burs of each type were tested. The burs were placed in sterilised bur stands and processed on the lower shelf in each of the washer-disinfectors.

\section{Calculation of log reduction}

For each decontamination technique tested, one control bur was contaminated with $S$. sanguis only and allowed to air dry. Viable bacteria were recovered and the TVC calculated. The TVC of $S$. sanguis from each test bur was determined. Log reduction (LR) in contamination was calculated using the following method: $L R=$ Log (TVC control) - Log (TVC test). ${ }^{15}$ 


\section{Statistical analysis}

The data were entered into an SPSS (Statistical Package for Social Sciences for Windows, Chicago, Illinois, USA) database and analysed. A Kolmogorov-Smirnov test was conducted to establish whether the data was normally distributed. Non-parametric tests (Kruskal-Wallis and Mann-Whitney) were used to investigate any statistical differences between the median LRs for the pre-sterilisation cleaning methods.

\section{RESULTS}

\section{Contamination of used dental burs}

The numbers of viable micro-organisms recovered from burs contaminated in general dental practice varied considerably between the different bur types. The TVC recovered from carbon steel No.8 round head burs ranged from 0 to $6.92 \times 10^{4} \mathrm{CFU} \mathrm{ml}^{-1}$, with a mean of $1.17 \times 104 \mathrm{CFU} \mathrm{ml}^{-1}$. The No.246 tungsten carbide burs produced TVCs ranging from 0 to $5.75 \times 10^{4} \mathrm{CFU} \mathrm{ml} \mathrm{m}^{-1}$. The mean TVC was $1.51 \times 10^{4} \mathrm{CFU} \mathrm{ml}{ }^{-1}$. The TVC of bacteria from the No.541 diamond burs ranged from 0 to $2.86 \times 10^{3} \mathrm{CFU} \mathrm{ml}^{-1}$, with a mean of $3.07 \times 10^{2}$ $\mathrm{CFU} \mathrm{ml} \mathrm{m}^{-1}$. The species of bacteria and fungi recovered from burs used in dental practice are shown in Table 1 .

\section{Decontamination assay}

The TVC of the $S$. sanguis culture used to inoculate test burs ranged from $4 \times 10^{7} \mathrm{CFU} \mathrm{ml} l^{-1}$ to $6.72 \times 10^{10} \mathrm{CFU} \mathrm{m}{ }^{-1}$, with a mean of $3.96 \times 10^{9} \mathrm{CFU} \mathrm{ml}{ }^{-1}$. The TVC of bacteria recovered from untreated control burs ranged from $1.1 \times 10^{6} \mathrm{CFU} \mathrm{ml}{ }^{-1}$ to $1.48 \times 10^{9} \mathrm{CFU} \mathrm{ml}{ }^{-1}$, with a mean of $1.96 \times 10^{8} \mathrm{CFU} \mathrm{ml}{ }^{-1}$.

Autoclaving alone failed to kill all test bacteria inoculated onto No.8 carbon steel round head burs and No.541 diamond burs (see Figures 1 and 2). Additionally, the presence of blood, or blood and saliva as additional contaminants increased the number of burs from which viable bacteria were recovered. No viable bacteria were recovered from contaminated No.246 tungsten carbide burs following autoclaving.

The results of the Kolmogorov-Smirnov test showed that the data was not normally distributed, so non-parametric tests were conducted to compare the median LRs of the six different pre-sterilisation cleaning methods. A Kruskal-Wallis test comparing the pre-sterilisation methods for all bur types and contaminants added showed a statistically significant difference $(\mathrm{p}<0.001)$ in the median LR achieved between all the techniques tested. Comparison of the difference in median LR achieved between the pre-sterilisation cleaning techniques for each bur type and contaminant added was done using a series of Mann-Whitney tests. The p-values for these tests are summarised in Table 3. By comparing medians, it was possible to show which pre-sterilisation cleaning test produced a greater log reduction in viable streptococci.

Manual scrubbing using a bur brush was significantly more effective when performed under water than in the air $(\mathrm{p}<0.001)$ in most cases, with the exception of tungsten carbide and carbon steel burs contaminated with streptococci and blood and diamond burs contaminated with streptococci and saliva or a mixture blood and saliva. A combination of manual scrubbing and autoclaving rendered all test bacteria non-viable. The enzymic agents proved very effective in reducing the numbers of viable bacteria. There was a significance difference $(p<0.001)$ in the median LR achieved between Gigasept Enzymatic and Alkazyme from tungsten carbide and diamond burs where the contaminant was streptococci and blood; Alkazyme was significantly more effective than Gigasept Enzymatic. A combination of immersion in enzymic agents and autoclaving killed all inoculated test bacteria. Both washer-disinfectors killed all inoculated test bacteria and both were significantly more effective $(\mathrm{p}<0.001)$ than manual scrubbing in air for all bur types and contaminants added. There was a significant difference $(\mathrm{p}<0.001)$ between the Miele G7830TD washer-disinfector and the
Table 1 Bacterial and fungal species recovered from burs used in dental practice

\begin{tabular}{l} 
Micro-organism \\
\hline Streptococcus \\
S. mutans \\
S. sanguis \\
S. milleri \\
Anaerobic streptococci \\
Lactobacillus spp. \\
Gemella \\
G. morbillorum \\
Staphylococcus spp. \\
Coagulase negative staphylococci \\
Corynebacteria spp. \\
Actinomyces spp. \\
Aerococcus viridans \\
Enterococcus avium \\
Stomatococcus mucillagenous \\
Black pigmented anaerobes \\
Prevotella spp. \\
Porphyromonas spp. \\
Veillonella spp. \\
Candida \\
C. albicans
\end{tabular}

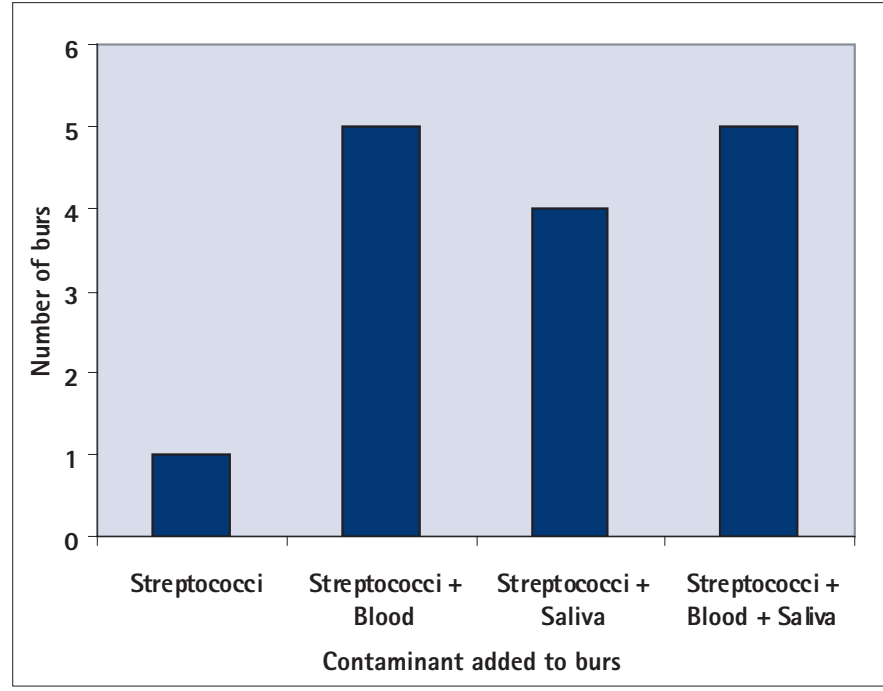

Fig. 1 Number of No.8 round head carbon steel burs $(n=25)$ from which viable Streptococcus sanguis were recovered following a $3.5 \mathrm{~min}, 134^{\circ} \mathrm{C}$, nonvacuum autoclave cycle

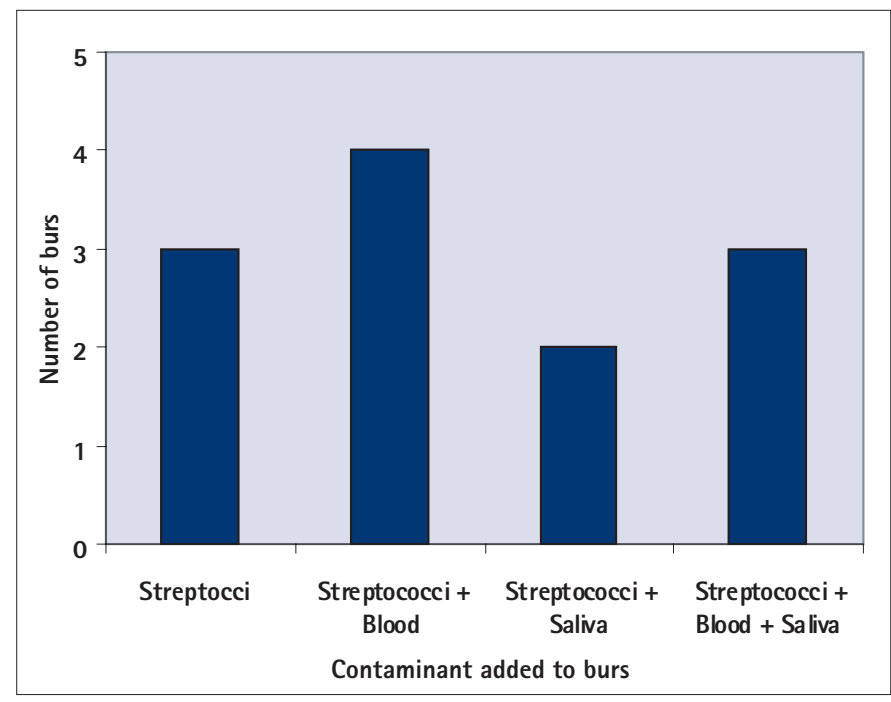

Fig. 2 Number of No.541 diamond burs $(n=25)$ from which viable Streptococcus sanguis were recovered following a $3.5 \mathrm{~min}, 134^{\circ} \mathrm{C}$, nonvacuum autoclave cycle 


\begin{tabular}{|c|c|c|c|c|c|c|}
\hline \multirow[t]{2}{*}{ Type of bur } & \multirow[t]{2}{*}{ Decontamination technique } & \multicolumn{2}{|c|}{ Log (TVC bacterial challenge) } & \multicolumn{3}{|c|}{ Median log reduction contaminant added } \\
\hline & & & Streptococci & Streptococci + Blood & Streptococci + Saliva & Streptococci + Blood + Saliva \\
\hline \multirow[t]{6}{*}{ No.8 round head carbon steel } & Manual scrubbing in air & 6.04 & 6.04 & 5.39 & 6.04 & 6.04 \\
\hline & Manual scrubbing under water & 9.17 & 7.57 & 6.66 & 8.87 & 8.87 \\
\hline & Gigasept Enzymatic & 8.61 & 8.52 & 5.66 & 8.60 & 8.60 \\
\hline & Alkazyme & 7.60 & 7.25 & 6.62 & 7.25 & 6.62 \\
\hline & Medisafe HSC-032 & 7.23 & $7.23^{*}$ & $7.23^{*}$ & $7.23^{*}$ & $7.23^{*}$ \\
\hline & Miele G 7830 TD & 8.61 & $8.61^{*}$ & $8.61^{*}$ & $8.61^{*}$ & $8.61^{*}$ \\
\hline \multirow[t]{6}{*}{ No.541 diamond } & Manual scrubbing in air & 6.89 & 2.51 & 1.91 & 4.01 & 2.11 \\
\hline & Manual scrubbing under water & 8.52 & 5.17 & 4.40 & 5.52 & 5.76 \\
\hline & Gigasept Enzymatic & 8.25 & 6.78 & 3.92 & 7.03 & 6.88 \\
\hline & Alkazyme & 8.39 & 8.07 & 8.07 & 8.02 & 8.07 \\
\hline & Medisafe HSC-032 & 7.09 & $7.09^{*}$ & $7.09^{*}$ & $7.09^{*}$ & $7.09^{*}$ \\
\hline & Miele G 7830 TD & 9.11 & $9.11^{*}$ & $9.11^{*}$ & $9.11^{*}$ & $9.11^{*}$ \\
\hline \multirow[t]{6}{*}{ No.246 tungsten carbide } & Manual scrubbing in air & 7.56 & 3.91 & 4.67 & 5.16 & 4.01 \\
\hline & Manual scrubbing under water & 6.94 & 6.44 & 4.74 & 6.94 & 6.44 \\
\hline & Gigasept Enzymatic & 7.85 & 7.18 & 3.42 & 7.18 & 4.97 \\
\hline & Alkazyme & 7.94 & 7.01 & 7.61 & 7.61 & 7.61 \\
\hline & Medisafe HSC-032 & 7.09 & $7.09^{*}$ & $7.09^{*}$ & $7.09^{*}$ & $7.09^{*}$ \\
\hline & Miele G 7830 TD & 7.32 & $7.32^{*}$ & $7.32^{*}$ & $7.32^{*}$ & $7.32^{*}$ \\
\hline
\end{tabular}

* Log reduction achieved is constant for this bur type and contaminant added

Medisafe HSC-032 machine for all bur types and contaminants added, with the Miele achieving a greater median LR in viable bacteria in all cases. It should be noted that the TVC of the bacterial challenge was greater for the tests using the Miele washer-disinfector than for the Medisafe machine.

The median LR in TVC of bacteria achieved by the different precleaning techniques investigated for each bur type and nature of contaminant is shown in Table 2 and illustrated graphically in Figures 3-5.

\section{DISCUSSION}

In this study, most of the used burs from dental practice were contaminated with potentially pathogenic species of bacteria and fungi. All used dental burs are a potential source of cross-infection and should be appropriately decontaminated prior to reuse.

The common presence of the facultative anaerobe, Streptococcus sanguis, from used dental burs influenced the selection of this bacterium as the test organism for the assay method. It is a recognised human pathogen and has been identified as the causative organism in bacterial endocarditis and meningitis. ${ }^{16,17}$ S. sanguis possesses specific proteins for binding to salivary, plasma and platelet proteins. ${ }^{18-20}$ It adheres to hydroxyapatite, composite restorative materials and metals, including dental amalgam, gold and non-precious alloys. ${ }^{21,22}$ Rough or hydrophobic surfaces are preferentially colonised by $S$. sanguis. ${ }^{23,24}$ S. sanguis therefore binds not only to the bur and any tooth tissue and restorative material contaminating its working end, but also to any salivary or blood proteins present. An effective pre-sterilisation method for dental burs must be capable of removing this tenacious bacterium. The method used for contaminating burs in this study simulates the clinical situation by using a commonly identified bacterial contaminant of used dental burs as the test organism, though in greater numbers than would be encountered in a clinical setting. The additional contamination of blood and saliva, or a mixture of blood and saliva simulates the likely contamination encountered during operative dental procedures.

This study showed that autoclaving alone was not effective in decontaminating carbon steel or diamond dental burs. The tungsten carbide burs produced no viable test bacteria after autoclaving alone, presumably because tungsten carbide does not provide a suitable substrate for binding of $S$. sanguis. Only the working end of each bur was contaminated in the study, but it should be noted that welded joints are susceptible to bacterial adherence, so contamination of this part of the bur could constitute a cross-infection risk. ${ }^{25}$

Although manual scrubbing using a bur brush under water proved an effective method of pre-sterilisation cleaning for No.8 round head carbon steel burs and No.246 tungsten carbide burs

Table 3 p-values from Kruskal-Wallis test and Mann-Whitney tests to compare the six pre-sterilisation cleaning techniques for each bur type and contaminant added

\begin{tabular}{|c|c|c|c|c|c|c|c|c|c|c|c|c|c|c|c|c|c|}
\hline \multirow[t]{2}{*}{ Bur type } & \multirow[t]{2}{*}{ Contaminant added } & \multirow[t]{2}{*}{$\begin{array}{l}\text { Overall p-value } \\
\text { (Kruskal-Wallis) }\end{array}$} & \multicolumn{15}{|c|}{$\begin{array}{l}\quad p \text {-value (Mann-Whitney) } \\
\text { Pre-sterilisation cleaning methods }(n=10)\end{array}$} \\
\hline & & & $0 \vee 1$ & $0 \vee 2$ & $0 \vee 3$ & $0 \vee 4$ & $0 \vee 5$ & $1 \vee 2$ & $1 \vee 3$ & $1 \vee 4$ & $1 \vee 5$ & $2 \vee 3$ & $2 \vee 4$ & $2 \vee 5$ & $3 \vee 4$ & $3 \vee 5$ & $4 \vee 5$ \\
\hline \multirow[t]{4}{*}{ Tungsten carbide } & Streptococci & $<0.001$ & $<0.001$ & $<0.001$ & $<0.001$ & $<0.001$ & $<0.001$ & 0.002 & 0.005 & $<0.001<$ & $<0.001$ & 0.58 & 0.02 & 0.14 & 0.14 & 0.14 & $<0.001$ \\
\hline & Streptococci + blood & $<0.001$ & 0.85 & $<0.001$ & $<0.001$ & $<0.001$ & $<0.001$ & 0.06 & $<0.001$ & $<0.001$ & $<0.001$ & $<0.001$ & $<0.001$ & $1<0.001$ & $1>0.99$ & $>0.99$ & $<0.001$ \\
\hline & Streptococci + saliva & $<0.001$ & $<0.001$ & $<0.001$ & $<0.001$ & $<0.001$ & $<0.001$ & 0.02 & $<0.001$ & $<0.001$ & $<0.001$ & 0.48 & 0.02 & 0.14 & $>0.99$ & $>0.99$ & $<0.001$ \\
\hline & $\begin{array}{l}\text { Streptococci + blood } \\
+ \text { saliva }\end{array}$ & $<0.001$ & $<0.001$ & $<0.001$ & 0.58 & $<0.001$ & $<0.001$ & 0.48 & $<0.001$ & $<0.001$ & $<0.001$ & 0.007 & 0.14 & 0.14 & $>0.99$ & $>0.99$ & $<0.001$ \\
\hline \multirow[t]{4}{*}{ Diamond } & Streptococci & $<0.001$ & $<0.001$ & $<0.001$ & $<0.001$ & $<0.001$ & $<0.001$ & 0.001 & $<0.001$ & $<0.001<$ & $<0.001$ & 0.02 & 0.48 & $<0.001$ & 0.002 & $<0.001$ & $1<0.001$ \\
\hline & Streptococci + blood & $<0.001$ & $<0.001<$ & $<0.001$ & $<0.001$ & $<0.001$ & $<0.001$ & 0.85 & $<0.001$ & $<0.001<$ & $<0.001$ & $<0.001$ & $<0.001$ & $1<0.001$ & 10.02 & $<0.001$ & $1<0.001$ \\
\hline & Streptococci + saliva & $<0.001$ & 0.003 & $<0.001$ & $<0.001$ & $<0.001$ & $<0.001$ & 0.03 & $<0.001$ & 0.002 & $<0.001$ & 0.005 & $5>0.99$ & $<0.001$ & 10.002 & $<0.001$ & $1<0.001$ \\
\hline & $\begin{array}{l}\text { Streptococci + blood } \\
\text { + saliva }\end{array}$ & $<0.001$ & 0.001 & $<0.001$ & $<0.001$ & $<0.001$ & $<0.001$ & 0.007 & 0.01 & 0.002 & $<0.001$ & 0.19 & $>0.99$ & $<0.001$ & 0.48 & $<0.001$ & $1<0.001$ \\
\hline \multirow[t]{4}{*}{ Carbon steel } & Streptococci & $<0.001$ & $<0.001$ & $<0.001$ & $<0.001$ & $<0.001$ & $<0.001$ & 0.14 & 0.74 & 0.14 & 0.02 & 0.002 & $2<0.001$ & 0.002 & $2>0.99$ & $<0.001$ & $1<0.001$ \\
\hline & Streptococci + blood & $<0.001$ & 0.007 & 0.58 & 0.002 & $<0.001$ & $<0.001$ & 0.06 & $>0.99$ & 0.48 & 0.002 & 0.12 & 0.002 & 20.002 & 20.02 & $<0.001$ & $1<0.001$ \\
\hline & Streptococci + saliva & $<0.001$ & $<0.001$ & $<0.001$ & $<0.001$ & $<0.001$ & $<0.001$ & 0.05 & 0.007 & $<0.001$ & 0.14 & 0.002 & 20.02 & $>0.99$ & $>0.99$ & $<0.001$ & $1<0.001$ \\
\hline & $\begin{array}{l}\text { Streptococci + blood } \\
+ \text { saliva }\end{array}$ & $<0.001$ & $<0.001$ & 0.003 & 0.003 & $<0.001$ & $<0.001$ & $<0.001$ & $<0.001$ & 0.002 & 0.002 & 0.12 & 0.48 & $>0.99$ & 0.14 & $<0.001$ & $<0.001$ \\
\hline
\end{tabular}




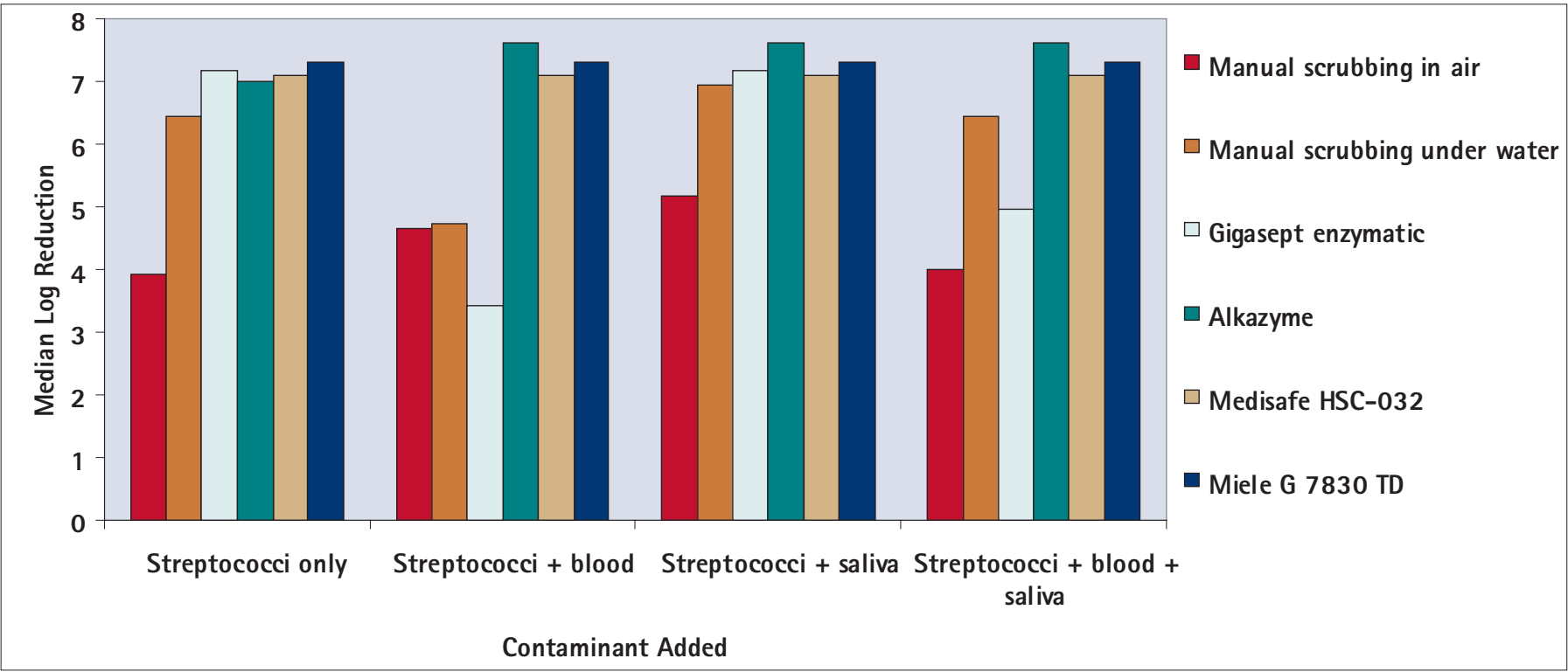

Fig. 3 Median log reduction in TVC of Streptococcus sanguis inoculated onto No.246 tungsten carbide burs achieved by various pre-sterilisation cleaning techniques

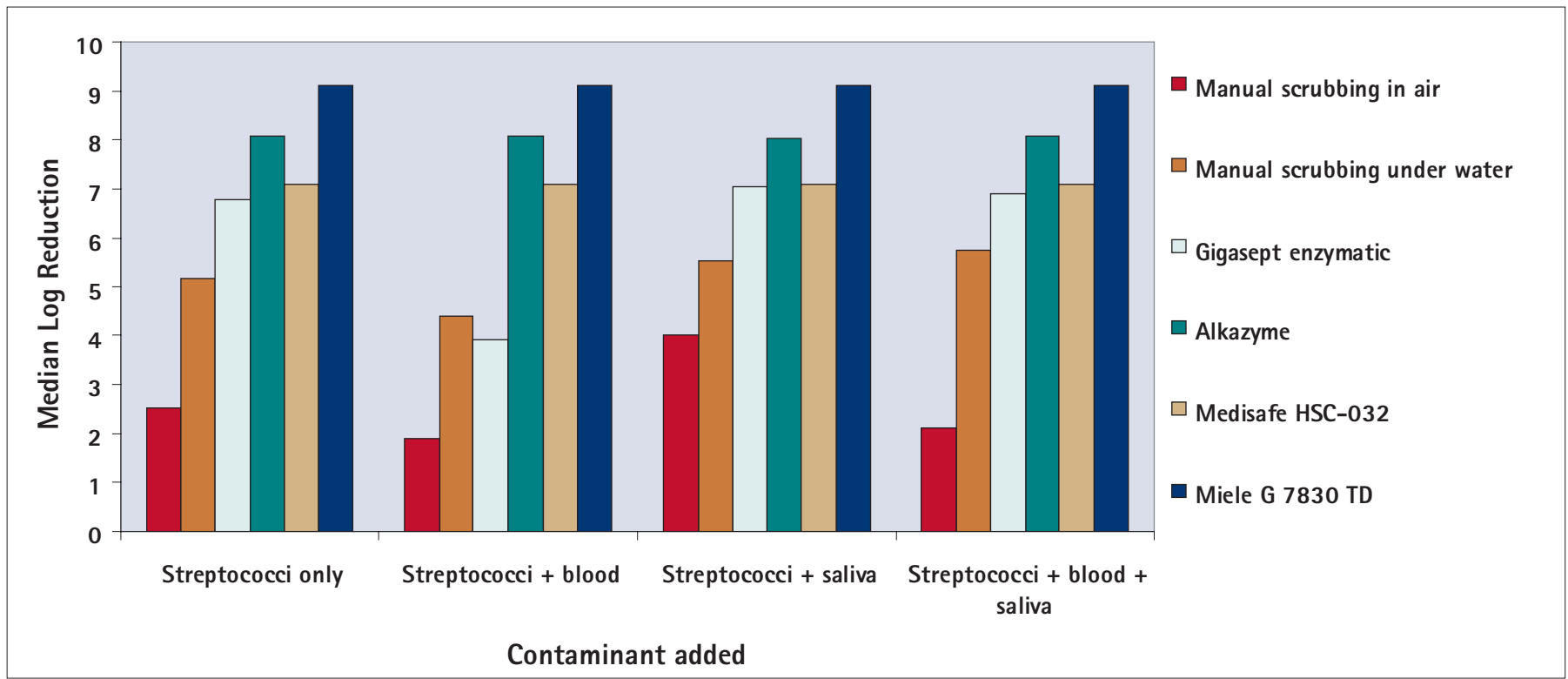

Fig. 4 Median log reduction in TVC of Streptococcus sanguis inoculated onto No. 541 diamond burs achieved by various pre-sterilisation cleaning techniques

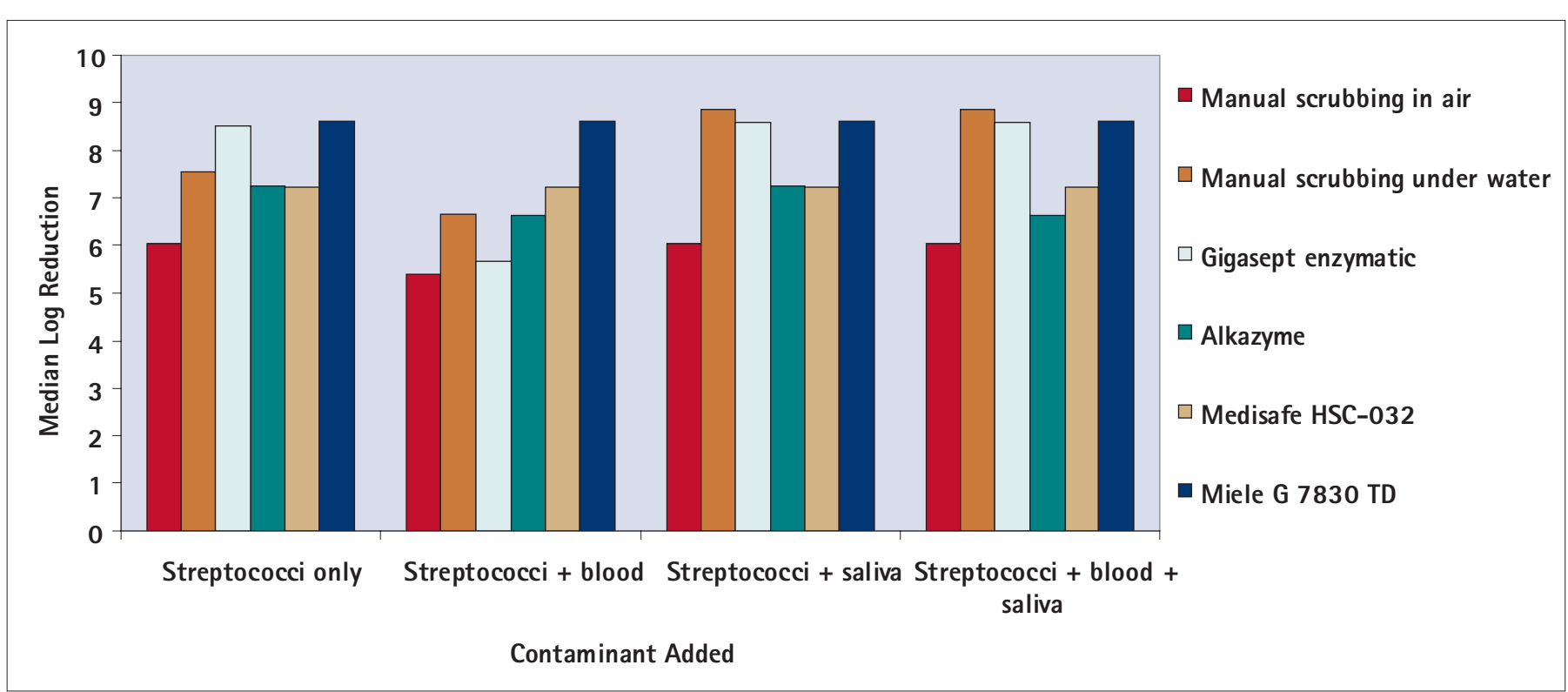

Fig. 5 Median log reduction in TVC of Streptococcus sanguis inoculated onto No.8 round head carbon steel burs achieved by various pre-sterilisation cleaning techniques 
when diligently applied, it proved a far less efficacious method for cleaning No.541 diamond burs. Diamond burs have a more complex architecture and may therefore be more difficult to clean using a bur brush. Manual scrubbing is extremely operator sensitive and may produce inconsistent results. It should not be recommended as a pre-sterilisation technique for dental burs due to the serious risk of cross-infection from puncture wounds, particularly to support staff.

Enzymic agents were very effective in reducing the TVC of inoculated bacteria, but their use is operator-dependant. Noncompliance with manufacturer's guidance on correct dilution of the agent, or immersion for shorter periods than recommended may adversely affect their efficacy. Continued use of the same solution throughout the day might result in recontamination of instruments already immersed and may also be detrimental to its effectiveness. Further research into the use of enzymic agents for pre-sterilisation cleaning of dental instruments is required.

The washer-disinfectors investigated in this study rendered all test bacteria non-viable. Burs contaminated in practice may harbour spore-forming bacteria and blood-borne viruses that may not be killed by a washer-disinfector and should be autoclaved after pre-cleaning. Washer-disinfectors have a reproducible closed cycle, require minimal handling of soiled instruments and may be verified by print-out, if the machine has a printer fitted. In this study, they were the most effective method of pre-sterilisation cleaning.

The ideal method of pre-sterilisation cleaning requires minimal handling of used instruments, does not create an aerosol of patient debris and produces a consistent, verifiable reduction in contamination. Every instrument is subjected to exactly the same, nonoperator-sensitive, closed cycle and a printed readout allows the process to be validated. Practitioners should consider the risk to their staff when adopting infection control procedures. In light of the risk of puncture wounds and the non-verifiable nature of manual cleaning, practitioners should be discouraged from continuing to use this technique. It is suggested that enzymic agents should be confined for use immediately post-operatively, for immersion of instruments prior to a verifiable method of pre-sterilisation cleaning. The authors recommend the use of washer-disinfectors for pre-sterilisation cleaning of contaminated dental burs.

The authors acknowledge the support of the Faculty of General Dental Practitioners (UK) and Dentsply (UK). Special thanks to Patricia Bilsborrow for her assistance.
1. British Dental Association. Infection Control in Dentistry, A12 Advice sheet. London, 2003.

2. Marsh P, Martin M. Oral Microbiology. 4th ed. Oxford: Wright, 1999.

3. Sanchez $E$, Macdonald G. Decontaminating dental instruments: testing the effectiveness of selected methods. J Am Dent Assoc 1995;126: 359-366.

4. Gureckis K M, Burgess J 0, Schwartz R S. Cutting effectiveness of diamond instruments subjected to cyclic sterilization methods. J Prosthet Dent 1991; 66: 721726.

5. Harkness N, Davies E H. The cleaning of dental diamond burs. Br Dent J 1983; 154: 42-45.

6. Sagripanti J L, Bonifacino A. Comparative sporicidal effect of liquid chemical germicides on three medical devices contaminated with spores of Bacillus subtilis. Am J Infect Control 1996; 24: 364-371.

7. Leontiou A P, Coogan M M, Aspinall S. Disinfection of dental diamond burs contaminated with hepatitis B virus. J Prosthet Dent 1999: 82:332-335.

8. Cafruny W A, Brunick A, Nelson D M, Nelson R F. Effectiveness of ultrasonic cleaning of dental instruments. Am J Dent 1995; 8: 152-156.

9. Bentley E M. The value of ultrasonic cleaners in dental practice. Br DentJ 1994; 177: 53-56.

10. Ramos-Gomez F, Ellison J, Greenspan D, Bird W, Lowe S, Gerberding J L. Accidental exposures to blood and body fluids among health care workers in dental teaching clinics: a prospective study. J Am Dent Assoc 1997: 128: 1253-1261.

11. Patterson C J, McLundie A C, Mackay A M. The effect of ultrasonic cleansing and autoclaving on tungsten carbide burs. Br Dent J 1988; 164: 113-115.

12. Miller C. Instrument cleaning involves multiple steps. Dentist 1990; 68: 23-25.

13. Booth J, Wilson E. An audit of cross infection control procedures in Lothian general dental practice. CPD Dentistry 2000; 1:51-56.

14. Villasenor A, Hill SD, Seale N S. Comparison of two ultrasonic cleaning units for deterioration of cutting edges and debris removal on dental burs. Pediatr Dent 1992; 14:326-330.

15. Robison R, Bodily H, Robinson D, Christensen R. A suspension method to determine reuse life of chemical disinfectants during clinical use. App/ Environ Microbio/ 1988; 54: 158-164.

16. Chotmongkol V, Panthavasit J, Vorachit M. Streptococcus sanguis meningitis: report of a case. J Med Assoc Thai 2002; 85: 839-841.

17. Parker M T, Ball LC. Streptococciand aerococciassociated with systemic infection in man. J Med Microbiol 1976; 9: 275-302.

18. Gong $\mathrm{K}$, Ouyang T, Herzberg M C. A streptococcal adhesion system for salivary pellicle and platelets. Infect Immun 1998; 66: 5388-5392.

19. Ganeshkumar N, Arora N, Kolenbrander PE. Saliva-binding protein (SsaB) from Streptococcus sanguis 12 is a lipoprotein. J Bacterio/ 1993; 175: 572-574.

20. Ericson D, Bratthall D, Bjorck L, Myhre E, Kronvall G. Interactions between human serum proteins and oral streptococci reveal occurrence of receptors for aggregated beta 2-microglobulin. Infect Immun 1979; 25: 279-83.

21. Yoshida Y, Wasaka $K$, Kajie Y, et al. Adherent bacteria cells in five dental materials: sonication effect. J Mater Sci Mater Med 1998; 9: 117-120.

22. Grivet $M$, Morrier J, Benay $G$, Barsotti 0 . Effect of hydrophobicity on in vitro streptococcal adhesion to dental alloys. J Mater Sci Mater Med 2000; 11: 637-642.

23. Wassall M, Embery G, Bagg J. The role of hydrophobicity in Streptococcus sanguis and Streptococcus salivarius adhesion to salivary fraction-coated hydroxyapatite. Colloids Surf B Biointerfaces 1995; 5: 143-152.

24. Drake D, Paul J, Keller J. Primary bacterial colonization of implant surfaces. Int J Oral Maxillofac Implants 1999; 14: 226-232.

25. Sreekumari K R, K N, Y K. Bacterial attachment to stainless steel welds: Significance of substratum microstructure. Biofouling 2001; 17: 303-316. 